OPEN ACCESS

Edited by:

Narasaiah Kolliputi,

University of South Florida, USA

Reviewed by:

Lei Liu,

University of Florida, USA

Khursheed Wani,

Johns Hopkins University, USA

*Correspondence:

Selva Rivas-Arancibia

srivas@unam.mx

Specialty section:

This article was submitted to

Oxidant Physiology,

a section of the journal

Frontiers in Physiology

Received: 22 October 2015 Accepted: 04 December 2015 Published: 23 December 2015

Citation:

Figueroa-Méndez $R$ and

Rivas-Arancibia S (2015) Vitamin C in Health and Disease: Its Role in the

Metabolism of Cells and Redox State in the Brain. Front. Physiol. 6:397. doi: 10.3389/fphys.2015.00397

\section{Vitamin C in Health and Disease: Its Role in the Metabolism of Cells and Redox State in the Brain}

\author{
Rodrigo Figueroa-Méndez and Selva Rivas-Arancibia *
}

Laboratorio de Estrés Oxidativo y Plasticidad Cerebral, Departamento de Fisiología, Facultad de Medicina, Universidad

Nacional Autónoma de México, México, Mexico

Ever since Linus Pauling published his studies, the effects of vitamin $\mathrm{C}$ have been surrounded by contradictory results. This may be because its effects depend on a number of factors such as the redox state of the body, the dose used, and also on the tissue metabolism. This review deals with vitamin $\mathrm{C}$ pharmacokinetics and its participation in neurophysiological processes, as well as its role in the maintenance of redox balance. The distribution and the concentration of vitamin $\mathrm{C}$ in the organs depend on the ascorbate requirements of each and on the tissue distribution of sodium-dependent vitamin C transporter 1 and 2 (SVCT1 and SVCT2). This determines the specific distribution pattern of vitamin $\mathrm{C}$ in the body. Vitamin $\mathrm{C}$ is involved in the physiology of the nervous system, including the support and the structure of the neurons, the processes of differentiation, maturation, and neuronal survival; the synthesis of catecholamine, and the modulation of neurotransmission. This antioxidant interacts with self-recycling mechanisms, including its participation in the endogenous antioxidant system. We conclude that the pharmacokinetic properties of ascorbate are related to the redox state and its functions and effects in tissues.

Keywords: vitamin C, pharmacokinetics, neurophysiology, oxidative stress, learning and memory processes

\section{INTRODUCTION}

Vitamin C is involved in the maintenance of body functions. However, there is a great deal of studies that show contradictory results about its effects. From the time it was first isolated in 1928, numerous studies have been done on its biochemical and pharmacokinetic properties, its functions and even the role of this molecule in neurophysiology. It is important to identify the role vitamin C has in the maintenance of oxide/reduction (redox) balance, as well as the possible effect it may have on the treatment of chronic degenerative diseases, autoimmune diseases and cancer. The purpose of this review is to update the current state of knowledge on vitamin $\mathrm{C}$ and the relevance it has in medicine since its effects are yet to be fully understood.

\section{Ascorbic Acid, Ascorbate, and Vitamin C}

Ascorbic acid is a neutrally charged molecule which can be protonated and become ascorbate. Depending on the $\mathrm{pH}$ of the medium in which it is located, ascorbic acid may lose the hydrogen ions attached to one of its two ionizable groups located at carbons $2^{\prime}$ and $3^{\prime}$, generating ascorbate monoanion or dianion (Tolbert et al., 1975; Markarian and Sargsyan, 2011; Du et al., 2012; Figure 1). Ascorbic acid is a white crystalline solid soluble in water; one of its important roles lies 


\section{Ascorbic acid Ascorbate monoanion Ascorbate dianion}

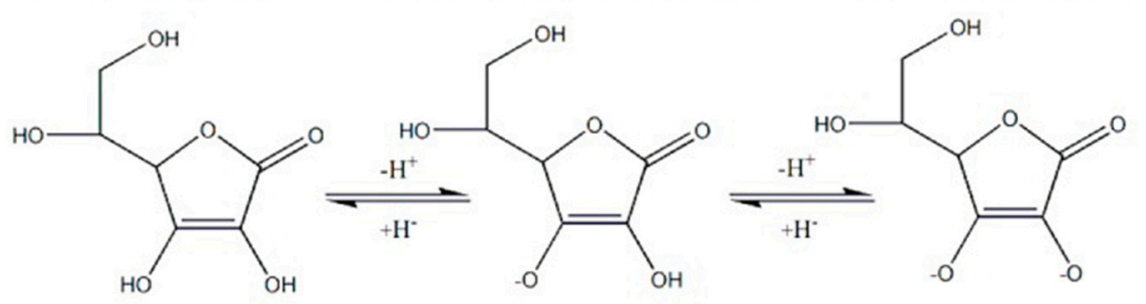

\begin{tabular}{c|c|c|c|}
\cline { 2 - 4 } pH 7 & $\begin{array}{c}\text { Lower } \\
\text { Concentration }\end{array}$ & \multicolumn{1}{c|}{$\begin{array}{c}\text { Higher } \\
\text { Concentration }\end{array}$} & $\begin{array}{c}\text { Lower } \\
\text { Concentration }\end{array}$ \\
\cline { 2 - 4 } acid pH & $\begin{array}{c}\text { Higher } \\
\text { Concentration }\end{array}$ & $\begin{array}{c}\text { Lower } \\
\text { Concentration }\end{array}$ & $\begin{array}{c}\text { Lower } \\
\text { Concentration }\end{array}$ \\
\cline { 2 - 4 } & &
\end{tabular}

FIGURE 1 | pH-dependent forms of vitamin $\mathbf{C}$. At $\mathrm{pH}$ 7, close to plasma $\mathrm{pH}$, the predominant form of vitamin $\mathrm{C}$ will be ascorbate monoanion, followed by ascorbic acid and, in very low concentrations, ascorbate dianion (0.005\%); in an acidic pH, the predominant form will be ascorbic acid.

in its biochemical function in redox processes. When we talk of vitamin $\mathrm{C}$, we refer to the group of ascorbic acid analogs that can be both synthetic and natural molecules (Huh et al., 1998; Raić-Mlić et al., 2000; Yamamoto et al., 2002).

\section{Biosynthesis}

Plants and many animals have the capacity to synthesize ascorbic acid through several biosynthesis pathways (Figure 2). In fish, amphibians, reptiles, and bird species belonging to older taxonomic orders the enzymes involved in vitamin $\mathrm{C}$ biosynthesis are located mainly in the kidneys, while in mammals and bird species from more recent orders these enzymes are found mainly in the liver (Grollman and Lehninger, 1957; Chatterjee et al., 1961). However, species such as teleost fish, some passeriform birds, guinea pigs, and some primates like humans, have lost the ability to synthesize ascorbic acid (Grollman and Lehninger, 1957; Linster and Van Schaftingen, 2007). The enzyme responsible for this deficiency is L-gulonolactone oxidase, which is highly mutated in humans despite having the gene encoding the protein, referred to as a pseudogene (Nishikimi and Yagi, 1991; Nishikimi et al., 1994; Valpuesta and Botella, 2004). For this reason, these species require ascorbic acid from the diet, mainly that synthesized by plants (Figure 2).

\section{PHARMACOKINETICS}

\section{Absorption Mechanisms}

Ascorbate is the main form of vitamin $\mathrm{C}$ in the human body (Rumsey and Levine, 1998). This molecule acts as a co-substrate for several enzymes that are important for the functioning of the organism. Its activity as an antioxidant includes the ability to be reversibly oxidized to ascorbyl radical and then to dehydroascorbate (DHA; Wells and Xu, 1994).

Both forms are ingested in the diet, since ascorbate can be oxidized in the gastrointestinal tract (GIT) by the presence of other substances that act as oxidizing agents [e.g., Iron (F3+) and some flavonoids] (Wilson, 2002). Ascorbate may also be oxidized as a result of food processing, either by cooking techniques or by improper storage techniques in the case of packaged products (Wilson, 2002).

\section{Sodium-Dependent Vitamin C Transporters (SVCTs)}

Two sodium-dependent vitamin $\mathrm{C}$ transporters have been described, SVCT1 and SVCT2; both are glycoproteins that transport ascorbate into the cell. SVCT1 is encoded by a gene that belongs to the family of solute carriers, group 23A, member 1 (SLC23A1) of 1797 bp, while the SLC23A2 gene of 1952 bp encodes SVCT2 (Daruwala et al., 1999). In addition, it has been documented that SVCT1 transports ascorbate nine times faster (Steiling et al., 2007) than SVCT2, while the latter has a higher affinity for ascorbate, with an apparent Km of $21.3 \mathrm{uM}$ for SVCT2 and of 252.0 uM for SVCT1 (Daruwala et al., 1999; Figure 3).

The properties of these two transporters are likely to be the explanation of their tissue distribution. SVCT1 is found mostly in epithelial tissues (e.g., small intestine and proximal tubule of the nephron), where the transport of ascorbate is greater than that required by the cells. On the other hand, SVCT2 is found mainly in brain, skeletal muscle, placenta, and eye, where the contribution of ascorbate is tightly controlled to maintain adequate tissue concentrations (Wilson, 2005; Figure 3.1). The transport mediated by these glycoproteins is a secondary active, saturable $\mathrm{Na}+$-dependent transport (Tsukaguchi et al., 1999).

\section{Glucose Transporters (GLUTs)}

There have been described 14 GLUT proteins belonging to the family of solute carriers, group 2A (SLC2A; Mueckler and Thorens, 2013). Within this group, only GLUT1 and GLUT3, and to a lesser extent GLUT4, have been found to have the 


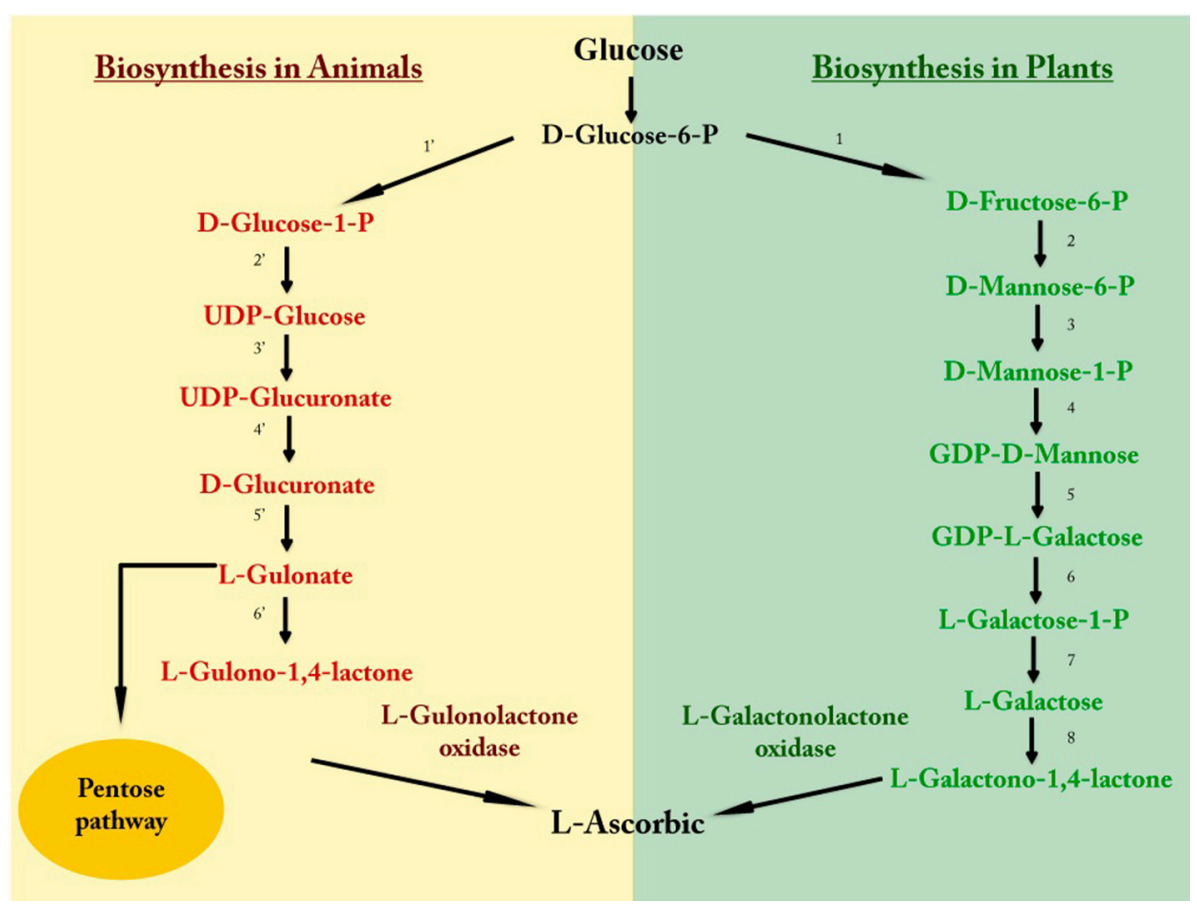

FIGURE 2 | Vitamin C biosynthesis. The initial metabolite of both pathways is glucose, which through a sequence of reactions involving an energy expenditure by the cell, synthesizes L-ascorbic acid. 1, Glucose-6-phosphate isomerase; 2, Mannose-6-phosphate isomerase; 3, Phosphomannomutase; 4, GDPD-mannose pyrophosphorylase; 5, GDP-D-mannose-3,5-epimerase; 6, Phosphodiesterase; 7, Sugar phosphatase; 8, L-galactose dehydrogenase; 1', Phosphoglucomutase; $2^{\prime}$, UDP-glucose pyrophosphorylase; 3', UDP-glucose dehydrogenase; 4', Glucuronate-1-phosphate uridylyltransferase and Glucurono kinase; 5', Glucuronate reductase; $6^{\prime}$, Aldono-lactonase.

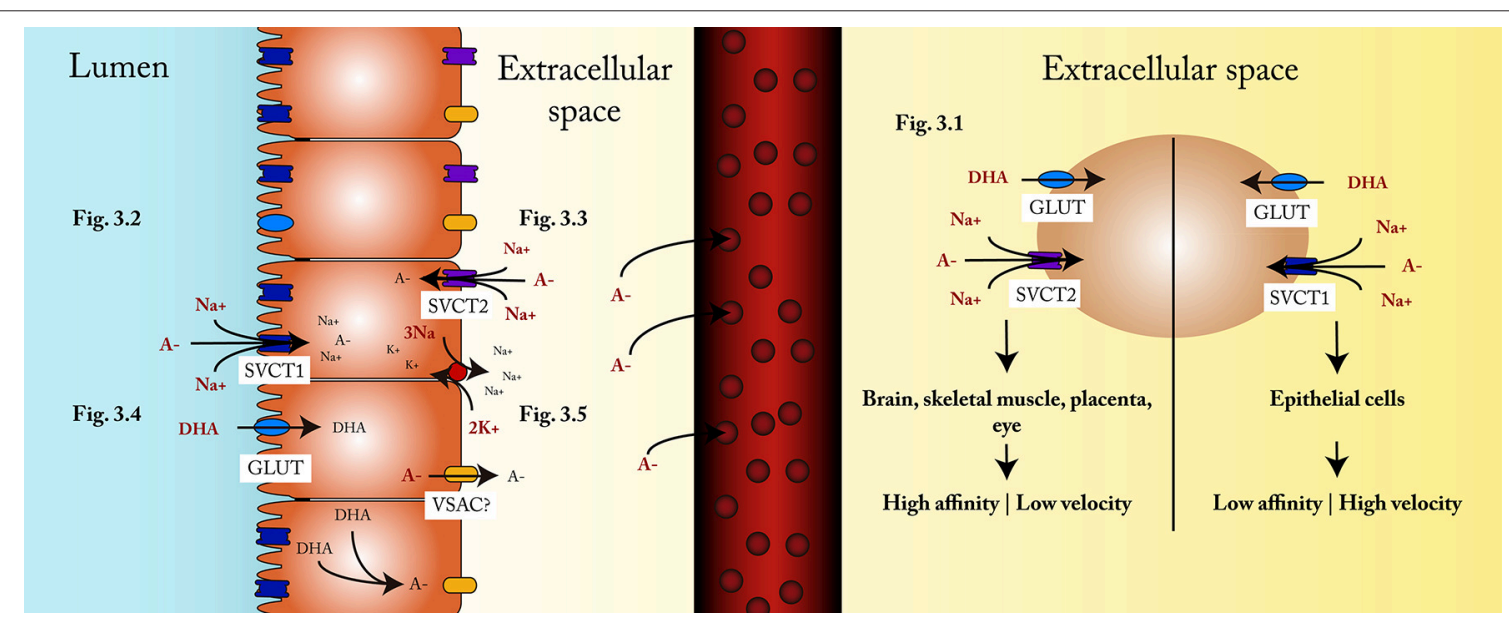

FIGURE 3 | Influx and efflux mechanisms. (3.1) The type of SVCT transporter depends on the characteristics and requirements in each cell, SVCT2 being more frequent in tissues that require a constant supply of ascorbate, even under vitamin C deficiency conditions, while SVCT1 is more frequent in cells responsible for tissue distribution of ascorbate. (3.2) Ascorbate transportation into the enterocyte occurs through SVCT1, coupled to a Na+/K+ATPase. (3.3) Under conditions of restricted ascorbic acid intake, the supply of ascorbate to the cell is carried out through the SVCT2 located in the basolateral membrane, which is also coupled to a $\mathrm{Na}+/ \mathrm{K}+\mathrm{ATPase}$. (3.4) DHA is transported into the enterocyte via GLUT transporters. (3.5) Within the enterocyte, DHA is reduced to ascorbate, then exits the cell and spreads to the capillaries through the extracellular space.

capacity to transport DHA (Li and Schellhorn, 2007). However, the ability of GLUT8 and GLUT2 to transport DHA into rat enterocytes has been shown (Corpe et al., 2013); this is important because GLUT8 and GLUT2 are also present in the human small intestine (Doege et al., 2000; Mueckler and Thorens, 2013).

Each of these transporters has its own characteristics and a specific tissue distribution. The GLUT1 isoform is widely 
expressed in the body; its presence in endothelial cells of the blood-brain barrier may contribute to the maintenance of concentration of ascorbate in the brain (Li and Schellhorn, 2007). GLUT3 is a high affinity transporter (low $\mathrm{Km}$ ) that initially was thought to be only present in neuronal cells, but now has been found in sperm, embryos, and leukocytes (Mueckler, 1994; Simpson et al., 2008). GLUT4 is expressed mainly in adipocytes and in skeletal and cardiac muscles; an important feature of this transporter is that it is found mostly within intracellular vesicles which attach to the plasma membrane in response to insulin (Mueckler, 1994). GLUT 2 has the peculiarity of being a low affinity transporter $(\mathrm{Km} \sim 17 \mathrm{mM})$; it is found in hepatocytes, enterocytes of the small intestine, proximal tubular cells, and $\beta$ pancreatic cells (Mueckler, 1994). GLUT8 is found in skeletal muscle, heart, small intestine, brain, and testis; its expression in testis can be suppressed by estrogens (Doege et al., 2000) Therefore, DHA transport is performed by a facilitated, saturable diffusion mechanism mediated by some GLUT transporters, which, unlike the transport of ascorbate, is $\mathrm{Na}+$ independent.

\section{Mechanisms of Entry into Enterocytes}

Both ascorbate and DHA can enter enterocytes via SVCT and GLUT transporters, respectively. The absorption pattern of ascorbate is opposite to that of glucose as ascorbate is better absorbed in the most distal segments (ileum) of the small intestine and, in smaller quantities, in the most proximal segments (duodenum). For its part, DHA is better absorbed in the jejunum while very little is absorbed in the distal segments of the ileum (Malo and Wilson, 2000).

One study showed that both SVCT1 and SVCT2 are expressed by enterocytes, but their distribution in the plasma membrane is polarized, as SVCT1 is found in the apical side of cells (Figure 3.2) and SVCT2 is present in the basolateral membrane (Boyer et al., 2005; Figure 3.3).

Part of the DHA absorbed corresponds to ascorbate oxidized in the lumen of the gastrointestinal tract (Wilson, 2002; Figure 3.4). It is yet to be defined which GLUT transporters are responsible for transporting DHA into the enterocyte. Although Corpe et al. proposed that GLUT2 and GLUT8 might be the transporters (Corpe et al., 2013), their study was performed using rats; additionally, other studies hold contradictory views. Some even point out that GLUT2 is not a DHA transporter (Cura and Carruthers, 2012), but others show that it is (Mardones et al., 2011).

\section{Efflux Mechanisms}

Although some hypotheses have been proposed, it is still unknown how ascorbate exits the cells. One of the hypotheses holds that epithelial enterocytes and renal proximal tubule cells swell when transporting some metabolites (Wilson, 2002, 2005). This process could activate volume sensitive anion channels (VSAC) located in the basolateral membrane which would allow the exit of ascorbate from inside the cell. It must be said that even though the effect has been observed, the protein has not been identified in enterocytes yet (Wilson, 2002, 2005; Corti et al., 2010; Figure 3.5). The VSAC are a family of membrane proteins that mediate the passive transport of organic anions in response to changes in intracellular osmolarity (Jackson and Strange, 1993; Strange and Jackson, 1995). This mechanism has been demonstrated in cultured astrocytes (Siushansian et al., 1996) and it is very likely to be present in enterocytes as well.

Another mechanism that has been proposed as transporter is an ascorbate-glutamate hetero-exchange (Grûnewald and Fillenz, 1984); however, some researchers believe its existence is unlikely and attribute the glutamate effect to the fact that glutamate favors the entry of $\mathrm{Na}+/ \mathrm{Cl}$ - activating $\mathrm{N}$-methyl-D-aspartate (NMDA) and non-NMDA receptors, glutamate transporters and voltagegated sodium channels (Vogler et al., 2013), causing the cell to swell and to activate VSAC (Corti et al., 2010). Ascorbate release, mediated by an exocytosis process (Von Zastrow et al., 1984) or by its passage through gap junctions (Wilson, 2005) has also been proposed as transporter. As for DHA, it is reduced to ascorbate inside the enterocyte by complex recycling mechanisms; then it exits the cell and goes into the extracellular space where it reaches the bloodstream through fenestrated capillaries that supply the mucosa of the small intestine (Wilson, 2002, 2005).

\section{Tissue Distribution}

The organs with the highest concentration of ascorbate are the adrenal glands $(550 \mathrm{mg} / \mathrm{kg})$, the brain $(140 \mathrm{mg} / \mathrm{kg})$, the liver $(125 \mathrm{mg} / \mathrm{kg})$, and in terms of size, the skeletal muscle with a concentration of $35 \mathrm{mg} / \mathrm{kg}$ (Richelle et al., 2006). The function performed by ascorbate in each cell of these organs will determine the type of transporter that is best suited for their local requirements. Regarding the central nervous system (CNS), the ascorbate located in the cerebrospinal fluid diffuses freely into the extracellular space of neurons and glia, where it is captured by both cell types via SVCT2 (except for astrocytes; García Mde et al., 2005; Savini et al., 2008; Gess et al., 2010). SVCT2 is the main transporter in the adrenal glands, (Savini et al., 2008); it maintains high concentrations of ascorbate in the chromaffin cells of the adrenal medulla, which are essential for the synthesis of catecholamines. SVCT1 is the most abundant transporter in the liver although SVCT2 is also expressed. A study carried out by Michels, Joisher and Hagen showed a decrease in the ascorbate uptake in rat hepatocytes due to a lower expression of the mRNA of SVCT1 associated with age (Michels et al., 2003).

In order for ascorbate to be able to reach tissues, it must go through the endothelial barrier of each tissue. One report demonstrated that ascorbate transport takes place primarily through a paracellular pathway (except in CNS) since transcellular transport is not correlated with the ascorbate transferred across the endothelium. Thus, ascorbate transport will depend on the narrowness of the space that exists between endothelial cells. This suggests that the process may be influenced by the rigidity conferred by ascorbate to the cytoskeleton of the cells forming the barrier (May et al., 2009).

\section{VITAMIN C AND CNS}

Ascorbate functions in the nervous system can be divided as follows: firstly, the interaction of ascorbate with the bloodbrain barrier as well as its medical implications; secondly, its effects on the process of neuronal differentiation, maturation and 
survival; thirdly, its effect on modulating neurotransmission and its participation in catecholamine synthesis. Finally, it has an antioxidant effect and it also plays a role in the learning and memory process as well as in the structure and support of the nervous system.

\section{Blood-Brain Barrier}

The blood-brain barrier is formed by three cells: the endothelium of the microvasculature of the brain, pericytes, and astrocytes. It has been proposed that astrocytes may induce the formation of the tight junctions between endothelial cells and influence the characteristic phenotype of the transporters of the bloodbrain barrier (e.g., GLUT1 and amino acid transporter L1; Abbott, 2002). For their part, pericytes appear to be involved in both maintaining the structural integrity of the vessel wall and regulating angiogenesis; they also seem to have a neuroimmunological effect due to their ability to phagocytize (Ballabh et al., 2004).

The main function of the blood-brain barrier is to maintain the internal microenvironment of the CNS, mediating the selective transport of nutrients, ions, waste products, drugs, and other substances (Abbott et al., 2006). Although ascorbate can penetrate into the CNS through the choroid plexus, it cannot cross through the blood-brain barrier because the tight junctions of the endothelium do not allow ascorbate transport through the paracellular pathway (Harrison and May, 2009). What is more, SVCT2 is not expressed in these cells (Qiao and May, 2009). Even though DHA can cross the blood-brain barrier through GLUT1 (Agus et al., 1997), it is not the main pathway through which ascorbate reaches the CNS; nevertheless it could be an important route from a therapeutic point of view. Huang et al. administered different doses of DHA intravenously before and after the induction of a stroke in mice. They found that DHA had a neuroprotective effect directly proportional to the dose administered. The protective effect was significant whether DHA was injected before or after the stroke (Huang et al., 2001).

Ascorbate distribution in the brain is not uniform. The amygdala, the hippocampus and the hypothalamus are the brain regions with the highest concentration of vitamin $\mathrm{C}$, but even in these structures the distribution is not homogeneous (Mefford et al., 1981). For example, the medial nucleus has a greater concentration of ascorbate in the hypothalamus than in either the preoptic nucleus or the posterior nucleus (Mefford et al., 1981). The substantia nigra is the brain region with the lowest concentration of ascorbate (Grümewald, 1993), which could be considered a susceptibility factor for oxidative stress if we consider that the synthesis of dopamine is pro-oxidant and needs ascorbate. Therefore, the requirements of ascorbate that dopaminergic neurons need may be the cause of the low ascorbate levels found in this brain structure.

\section{Vitamin C and Neuronal Differentiation, Maturation, and Survival}

The effect of ascorbate on the differentiation of embryonic stem cells into neurons in vitro is associated with an increase in the expression of genes involved in this process (Harrison and May, 2009). Lee et al. found that cells treated with ascorbate significantly increased the expression of NeuroD, Notch, BMP2, and BMP7, genes associated with the differentiation of neuronal and astrocytic cells. The same study demonstrated that vitamin $\mathrm{E}$ and glutathione do not have the same effect as ascorbate on neuronal cell differentiation so that the mechanism involved might not be directly related with its antioxidant effect (Lee et al., 2003). An increase in neurite formation in neurons in vitro due to the potentiating effect of 2-glucoside-L-ascorbic acid (ascorbate analog) on the nerve growth factor (NGF) has also been shown. This is an effect that the authors also attributed to a different mechanism given its antioxidant properties (Haramoto et al., 2008). An increase in the expression of brain-derived neurotrophic factor (BDNF) associated to the presence of ascorbate has also been observed in cell culture. BDNF activates the Ras-MAP kinase pathway, which contributes to cell survival by enhancing the expression of the enzymes of the endogenous antioxidant system [superoxide dismutase (SOD), glutathione peroxidase and glutathione reductase] (Grant et al., 2005).

\section{Vitamin C, Catecholamine Biosynthesis and Modulation of Neurotransmission}

As it was said before, ascorbate plays an important role in the synthesis of catecholamines, particularly dopamine and norepinephrine. Seitz et al. proposed that the modulatory effect of ascorbate can be divided into short and a long term. The short term refers to its participation as a co-substrate for tyrosine hydroxylase and dopamine- $\beta$-hydroxylase; and the long term effect, to the increased gene expression of tyrosine hydroxylase, probably through a mechanism that involves an increase in intracellular cAMP; however, the latter is still just a hypothesis (Seitz et al., 1998). Studies in ascorbate-deficient guinea pigs showed that the subjects had high dopamine and low norepinephrine levels due to alterations in the catalysis mediated by dopamine- $\beta$-hydroxylase; the levels were normalized even with low ascorbate concentration in the brain (Harrison and May, 2009). There are also reports which state that ascorbate promotes and maintains the differentiation of dopaminergic cells derived from midbrain neural precursors in vitro (Yan et al., 2001). Yu et al. carried out a study to identify the genes involved in the differentiation of these cells, and they found the upregulation of up to 92 genes and the downregulation of 118 genes, varying according to the stage of cell differentiation (Yu et al., 2004). An increase in the susceptibility to excitotoxicity mediated by the NMDA glutamate receptor in mice with SVCT2 deficiency has also been shown (Qiu et al., 2007). This mechanism can be explained either by an antioxidant effect of ascorbate on reactive oxygen species (ROS) generated by the activation of the receptor or by the interaction of ascorbate with a redox modulation site at the NMDA receptor level (Majewska et al., 1990). Other authors have described the effect of ascorbate as an inductor of the liberation of gonadotropins (luteinizing hormone and follicle-stimulating hormone) (Karanth et al., 2001). What they propose is that ascorbate released by the vesicles of the gonadotrope cells is recaptured by SVCT2 via an unknown mechanism and facilitates the entry of $\mathrm{Ca}^{2+}$ into the cell, which interacts with calmodulin and induces an increase in the activity of neuronal nitric oxide synthase (nNOS). 
Nitric oxide (NO) activates guanylate cyclase increasing the amount of cGMP. Finally, cGMP activates the protein kinase $\mathrm{C}$ (PKC), leading to exocytosis of gonadotropine (Karanth et al., 2001).

\section{Vitamin C, Learning, and Memory}

Parle and Dhingra injected doses of 60 and $120 \mathrm{mg} / \mathrm{kg}$ of ascorbic acid intraperitoneally to mice with drug-induced amnesia via the administration of diazepam and scopolamine and to mice that acquired amnesia naturally with age (Parle and Dhingra, 2003). Using the elevated plus maze and the passive avoidance test, the authors concluded that ascorbic acid improved learning and memory in old mice and protected the mice in the group that received the drugs (Parle and Dhingra, 2003). Similarly, other studies have shown that the combination of vitamin $\mathrm{C}$ and vitamin $\mathrm{E}$ can have beneficial effects preventing memory alterations (Delwing et al., 2006; Hasanein and Shahidi, 2010). However, it has not been possible to demonstrate the reproducibility of these results nor their efficacy in human studies focused on the prevention and treatment of dementia and Alzheimer's disease (Boothby and Doering, 2005; Fillenbaum et al., 2005).

Studies conducted in our laboratory have demonstrated that vitamin $\mathrm{C}$ effects on learning and memory are dependent on the redox balance state. When we gave a low dose of vitamin $\mathrm{C}$ $(50 \mathrm{mg} / \mathrm{kg}$ ) to healthy rats, their retention latency in the passive avoidance test decreased. Then, when we exposed a group of rats to an acute dose of ozone $(0.7 \mathrm{ppm})$ without vitamin $\mathrm{C}$, the retention latency in the passive avoidance test also decreased. Nevertheless, when we gave the same dose of vitamin $C$ to rats exposed to ozone, the retention latency was similar to that of the control, demonstrating a protective effect of the vitamin (Graphic 1). Subsequently, we compared these results with the lipid peroxidation levels in the hippocampus and we observed a relationship between the oxidative damage and the deficit in the passive avoidance test (Graphic 2). This showed a prooxidant effect of low dose vitamin $\mathrm{C}$ in a redox equilibrium and an antioxidant effect at any doses in an oxidative stress state (Dorado-Marínez et al., 1998).

\section{Vitamin C and CNS Structure}

Ascorbate has an important role in the synthesis of collagen and elastin, components of the blood vessels that supply the neural tissue and the basal lamina (Harrison and May, 2009); moreover, the role of ascorbate as an inductor of myelination mediated by Schwann cells has also been demonstrated. Fernandez-Valle et al. observed that adding ascorbate to cultures of Schwann cells with ganglion neurons favored the production of the basal lamina, essential for the induction of myelination, and seemed to induce protein zero mRNA (PZM), which is a major component of myelin; however, the mRNA expression of this protein was not exclusive of the ascorbate culture (FernándezValle et al., 1993). It has also been shown that myelination occurs in the presence or absence of ascorbic acid and that the differences under these culture conditions were dependent on laminin (Podratz et al., 2001). Other authors have described that p38, a member of the family of MAP kinases, plays an
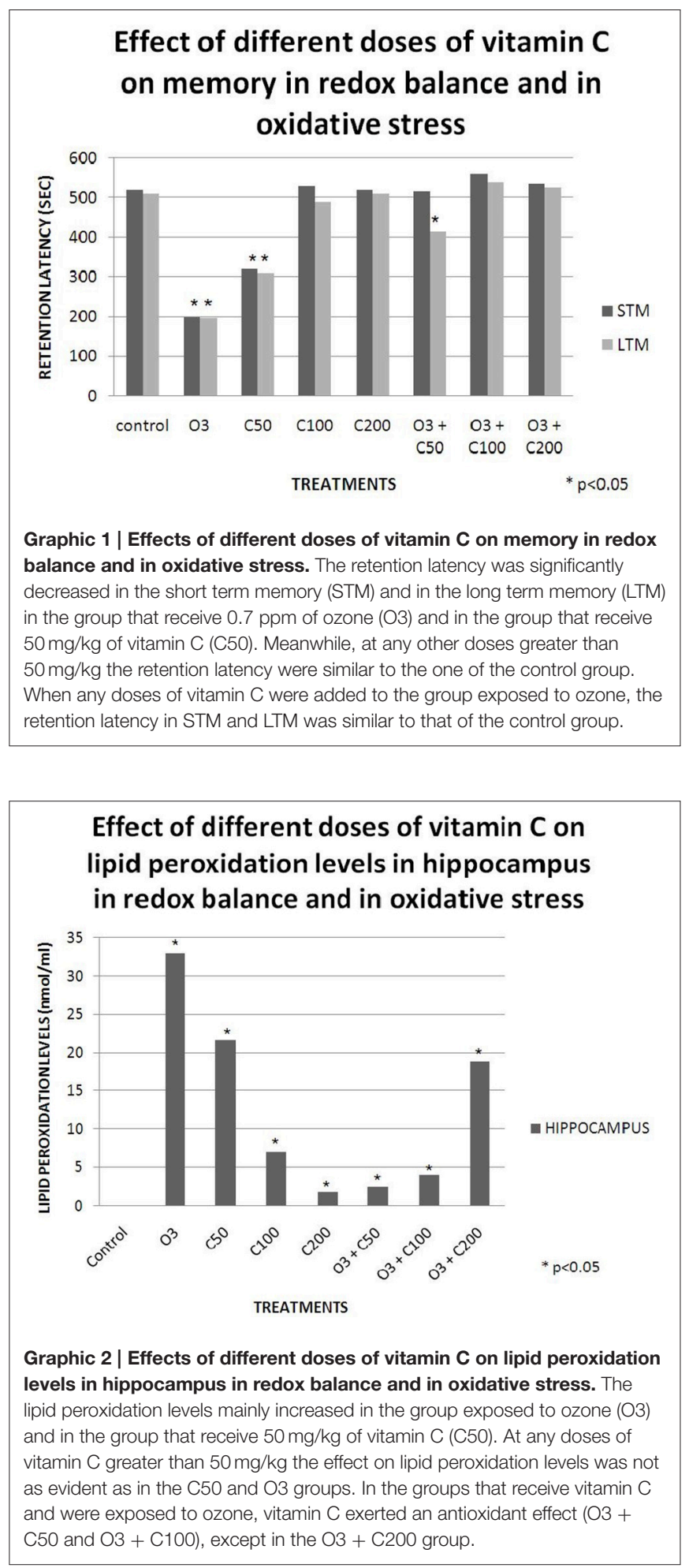

important role during the early stages of myelination induced by both ascorbate and laminin (Fragoso et al., 2003). Therefore, the main effect of ascorbate on myelination is probably due to the maintenance of the structural integrity of the basal lamina. 


\section{Antioxidant Role of Vitamin C in CNS}

The brain consumes $20 \%$ of the total body oxygen and has a high metabolic rate, making it a readily oxidizable tissue (Erecińska and Silver, 2001). These conditions justify the importance of the presence of antioxidants in the brain, which are needed to maintain the redox balance. The distribution of these antioxidants is not uniform since neurons can reach intracellular ascorbate concentrations of $10 \mathrm{mM}$ and a glutathione concentration of $2.5 \mathrm{mM}$ as opposed to what happens in glia where the concentration of ascorbate is $2.5 \mathrm{mM}$ and the one of glutathione is $3.8 \mathrm{mM}$ (Rice and Russo-Mena, 1997). The uneven distribution of ascorbate is due to the fact that SVCT2 is preferentially expressed in neurons; while in astrocytes ascorbate concentrates through the intracellular reduction of DHA which enters the cell via GLUT1. The physiological significance of this unequal distribution is the supply of ascorbate to the neuron. An increase in the expression of mRNA related to the translation of SVCT2 in both neurons and astrocytes has been proven in rats with induced cerebral ischemia, probably as a cellular protective mechanism against oxidative stress induced by ischemia (Berger et al., 2003). Some researchers have studied the interaction of ascorbate with other antioxidants such as $\alpha$ tocopherol (Niki et al., 1995) and gluthation (Puskas et al., 2000) as well as the possible therapeutic applications of this interaction, e.g., in the prevention of Alzheimer's disease (Morris et al., 1998).

\section{ROLE IN REDOX BALANCE}

There is a constant balance between oxidants and antioxidants in the body that helps to maintain "redox homeostasis." This means that when there is an increase the production of ROS, the body's response will be to increase of the activity of endogenous antioxidant systems through a mechanism of redox signaling (Valko et al., 2007). In addition, antioxidants can be obtained from exogenous sources; along with the endogenous antioxidant system, these exogenous antioxidants play an important role in maintaining the redox balance. The endogenous antioxidant systems comprise antioxidant enzymes (e.g., catalase, superoxide dismutase, and glutathione peroxidase) and antioxidant molecules (e.g., glutathione and thioredoxin; Dröge, 2002). Vitamin C, vitamin E and flavonoids are among the exogenous antioxidant molecules ingested in the diet. There are also molecules that function as metal chelators (e.g., lactoferrin and transferrin), avoiding the production of the hydroxyl radical through the Fenton and Haber-Weiss reaction (Valko et al., 2007). An increase in reactive oxygen and nitrogen species that exceeds the ability of the antioxidant system to counteract the increase of ROS leads to an "oxidative stress state."

The antioxidant effect of ascorbate is due to its ability to donate electrons from both the second and third carbon (Padayatty et al., 2003; Mahfouz and Kummerow, 2004). It has also been demonstrated that ascorbate is more effective than thiols, $\alpha$-tocopherol, and urate to prevent lipid peroxidation in plasma. Research reported that the higher the concentration of ascorbate in blood is, the greater the time it is required to initiate lipid peroxidation with no pro-oxidant effects, even in ascorbate serum concentrations of $5 \mathrm{mM}$ achievable only parenterally (Frei et al., 1989).

\section{Recycling Mechanisms}

To prevent the loss of intracellular concentrations of ascorbate and other antioxidant molecules such as glutathione, cells have recycling mechanisms formed by exogenous antioxidants and the endogenous antioxidant system.

The ascorbyl radical is a relatively stable molecule with an average life of 10-5s (Buettner, 1993; Padayatty et al., 2003). Its low reactivity is due to the ability of the unpaired electron to resonate between carbons $1^{\prime}$ and 3' (May, 1999) without interacting with O2 (Bielski and Richter, 1975). Two ascorbyl radicals can react with each other through a dismutation reaction in which one molecule is reduced to ascorbate and the other is oxidized to DHA. Another mechanism involved in the reduction of the ascorbyl radical is the NADH-dependent system mediated by the ascorbyl free radical reductase (AFR reductase) located in the cell membrane (May et al., 2001). Two types of AFR reductases have been described, those which are transmembrane and those found in the inner membrane. Both enzymes seem to be at a convenient location since the ascorbyl radical is formed in the plasma membrane by the reduction of $\alpha$-tocopherol; thereby counteracting the radicals generated in the intracellular side (May et al., 2001). The $\alpha$-tocopherol is a lipid antioxidant located near the surface of membranes and lipoproteins where it interacts with ascorbate, which is in the liquid phase of the interface (Niki et al., 1995). By donating an electron, $\alpha$-tocopherol is oxidized and converted into $\alpha$-tocopheryl radical, returned to its reduced form by the oxidation of ascorbate interface (Niki et al., 1995).

Thioredoxins are cellular proteins that catalyze the reduction of disulphides in different enzymes (e.g., ribonucleotide reductase) through the transfer of an electron from their thiol group (Arnér and Holmgren, 2000). Thioredoxin reductase is the enzyme responsible for keeping thioredoxin in its reduced form; however, there are reports of the ability of this enzyme to recycle DHA and ascorbyl radical into ascorbate by an NADPH-dependent process in cytosol (Mustacich and Powis, 2000). The glutathione and dihydrolipoic acid are capable of reducing DHA to ascorbate, besides dihydrolipoic acid can also reduce the ascorbyl radical (Kagan et al., 1992; Valko et al., 2007). The relevance of studying these recycling mechanisms is that many of them can be altered in a chronic oxidative stress state, making it more difficult to maintain normal ascorbate concentrations; thereby increasing the requirements for vitamin $\mathrm{C}$ in some subjects.

\section{Pro-oxidant Effect of Vitamin C}

The pro-oxidant ability of ascorbate is associated with the presence of free dissolved metals. A prooxidant effect of ascorbate dependent on the time at which it was administered to rats has been demonstrated (Kang et al., 1998). After injecting paraquat-dichloride intraperitoneally, the researchers recorded an increase in ethane exhalation (oxidative stress marker) and observed lung tissue damage under the microscope. When $10 \mathrm{mg} / \mathrm{kg}$ of ascorbate were administered intravenously prior 
to the injection of paraquat dichloride, a protective effect was observed; however, when ascorbate was administered $1 \mathrm{~h}$ after the paraquat dichloride injection, both ethane and tissue damage had increased. The explanation proposed by that study was that the interaction of ascorbate with free metals caused the tissue damage (Kang et al., 1998).

Another study reported an increase in 8-oxoadenine levels (DNA oxidative damage marker) and, paradoxically, a decrease in 8-oxoguanosine levels from basal measurements when supplementing 30 healthy volunteers with $500 \mathrm{mg} /$ day of vitamin C for 6 weeks, compared to the results observed with the placebo group (Podmore et al., 1998). When working with six healthy volunteers, other authors found that the intravenous administration of 750 or $7500 \mathrm{mg}$ of vitamin C did not increase the levels of lipid peroxides nor 8-oxoguanosine (Mühlhöfer et al., 2004). Therefore, some have criticized the results published by Podmore et al. suggesting possible methodological errors (Levine et al., 1998).

Chen et al. demonstrated a susceptibility effect of different types of cancer cells at pharmacological doses $(0.3-20 \mathrm{mM})$ of vitamin $\mathrm{C}$ in vitro. The mechanism was attributed to the ability of ascorbate to produce $\mathrm{H}_{2} \mathrm{O}_{2}$ in the extracellular space only when the ascorbyl radical levels were $>100 \mathrm{nM}$ (Chen et al., 2007). They also found that the production of $\mathrm{H}_{2} \mathrm{O}_{2}$ depended on the presence of redox-active metal centers of proteins (Chen et al., 2005, 2008), which led them to study this effect in a mouse model. They demonstrated a significant decrease in tumor cell growth and tumor weight due to a pro-drug effect of vitamin $\mathrm{C}$ (Chen et al., 2008).

A process of ascorbate autoxidation has been proposed when ascorbate is found in its dianionic form. In their review, $\mathrm{Du}$, Cullen and Buettner described that the concentration of dianionic ascorbate increases by a factor of 10 for every $\mathrm{pH}$ unit increase (Du et al., 2012). An increased susceptibility to auto-oxidation of dianionic ascorbate has been shown as well (Williams and Yandell, 1982); however, this process does not occur under physiological pH (Buettner, 1988). The possible effect of dianionic ascorbate under pathological conditions with altered $\mathrm{pH}$ is yet to be determined.

\section{CLINICAL PERSPECTIVE}

Given the effect of vitamin $\mathrm{C}$ on normal physiology, it is apparent that it plays a role in the maintenance of homeostasis. Nevertheless, it has not been possible to unify the criteria for its clinical use as previous studies have not taken into account the variability of its antioxidant effect, which depends on the redox state of the patient, the dose, and the right route of administration to achieve pharmacological concentrations.

We consider it necessary to continue the study of the therapeutic effects of vitamin $\mathrm{C}$ on neurodegenerative diseases, chronic inflammatory diseases, and cancer using vitamin $\mathrm{C}$ as a support for patients to decrease the oxidative stress caused by pathological entities.

\section{CONCLUSIONS}

The pharmacokinetic properties of ascorbate are intimately related with the functions it performs in tissues since its distribution and concentration in the different organs of the body depend on their requirements of vitamin C. In addition, there exists a specific distribution pattern of ascorbate in each organ which, in brain regions as the substantia nigra, is yet to be fully explained. This region has the lowest levels of vitamin $\mathrm{C}$ in the brain, a major topic due to the relationship that has been established between oxidative stress and Parkinson's disease.

In addition, the distinction between physiological and pharmacological doses of vitamin $\mathrm{C}$, determined by the route of absorption as well as by the pro-oxidant and antioxidant effect of different doses of vitamin $C$ dependent of the redox balance of the individual, allows us to understand why some previous studies have failed to demonstrate the health benefits of vitamin $\mathrm{C}$.

Finally, the role of vitamin $\mathrm{C}$ in health is related to the maintenance of the internal microenvironment determined by the redox balance, proven to be altered in diseases such as obesity, cancer, neurodegenerative diseases, hypertension and autoimmune diseases. This role should be the focus of future research using vitamin $\mathrm{C}$ as an adjunct in patient treatment.

\section{ACKNOWLEDGMENTS}

The authors thank Mirza Rojas-Santoyo for her edition review, Gabino Borgonio-Perez for his technical assistance and the Universidad Nacional Autónoma de México and the Dirección General de Apoyo al Personal Académico for the support for this project: DGAPA N ${ }^{\circ}$ IN221114

\section{REFERENCES}

Abbott, N. J. (2002). Astrocyte-endothelial interactions and blood-brain barrier permeability. J. Anat. 200, 523-534. doi: 10.1046/j.1469-7580.2002.00047_13.x

Abbott, N. J., Rönnbäck, L., and Hansson, E. (2006). Astrocyte-endothelial interactions at the blood-brain barrier. Nat. Rev. Neurosci. 7, 41-53. doi: $10.1038 / \mathrm{nrn} 1824$

Agus, D. B., Gambhir, S. S., Pardridge, W. M., Spielholz, C., Baselga, J., Vera, J. C., et al. (1997). Vitamin C crosses the blood-brain barrier in the oxidized form through the glucose transporters. J. Clin. Invest. 100, 2842-2848. doi: 10.1172/JCI119832

Arnér, E. S., and Holmgren, A. (2000). Physiological functions of thioredoxin and thioredoxin reductase. Eur. J. Biochem. 267, 6102-6109. doi: 10.1046/j.14321327.2000.01701.x

Ballabh, P., Braun, A., and Nedergaard, M. (2004). The blood-brain barrier: an overview structure, regulation, and clinical implications. Neurobiol. Dis. 16, 1-13. doi: 10.1016/j.nbd.2003.12.016

Berger, U. V., Lu, X. C., Liu, W., Tang, Z., Slusher, B. S., and Hediger, M. A. (2003). Effect of middle cerebral artery occlusion on mRNA expression for the sodium-coupled vitamin C transporter SVCT2 in rat brain. J. Neurochem. 86, 896-906. doi: 10.1046/j.1471-4159.2003. 01891.x 
Bielski, B. H., and Richter, H. W. (1975). Some properties of the ascorbate free radical. Ann. N.Y. Acad. Sci. 258, 231-237. doi: 10.1111/j.17496632.1975.tb29283.x

Boothby, L. A., and Doering, P. L. (2005). Vitamin C and vitamin E for Alzherimer's disease. Ann. Pharmacother. 39, 2073-2080. doi: 10.1345/aph.1E495

Boyer, J. C., Campbell, C. E., Singurdson, W. J., and Kuo, S. M. (2005). Polarized localization of vitamin C transporters SVCT1 and SVCT2, in epithelial cells. Biochem. Biophys. Res. Commun. 334, 150-156. doi: 10.1016/j.bbrc.2005. 06.069

Buettner, G. R. (1988). In the absence of catalytic metals ascorbate does not autoxidize at $\mathrm{pH} 7$ : ascorbate as a test for catalytic metals. J. Biochem. Biophys. Methods 16, 27-40. doi: 10.1016/0165-022X(88)90100-5

Buettner, G. R. (1993). The pecking order of free radicals and antioxidants: lipid peroxidation, $\alpha$ - tocopherol, and ascorbate. Arch. Biochem. Biophys. 300, 535-543. doi: 10.1006/abbi.1993.1074

Chatterjee, I. B., Kar, N. C., Ghosh, N. C., and Guha, B. C. (1961). Aspects of ascorbic acid biosynthesis in animals. Ann. N.Y. Acad. Sci. 92, 36-56. doi: 10.1111/j.1749-6632.1961.tb46105.x

Chen, Q., Espey, M. G., Krishna, M. C., Mitchell, J. B., Corpe, C. P., and Buettner, G. R. (2005). Pharmacologic ascorbic acid concentrations selectively kill cancer cells: action as a pro-drug to deliver hydrogen peroxide to tissue. Proc. Natl. Acad. Sci. U.S.A. 102, 13604-13609. doi: 10.1073/pnas.0506 390102

Chen, Q., Espey, M. G., Sun, A. Y., Lee, J. H., Krishna, M. C., Shacter, E., et al. (2007). Ascorbate in pharmacologic concentrations selectively generates ascorbate radical and hydrogen peroxide in extracellular fluid in vivo. Proc. Natl. Acad. Sci. U.S.A. 104, 8749-8754. doi: 10.1073/pnas.0702854104

Chen, Q., Espey, M. G., Sun, A. Y., Pooput, C., Kirk, K. L., Krishna, M. C., et al. (2008). Pharmacologic doses of ascorbate act as a prooxidant and decreases growth of aggressive tumor xenografts in mice. Proc. Natl. Acad. Sci. U.S.A. 105, 11105-11109. doi: 10.1073/pnas.0804226105

Corpe, C. P., Eck, P., Wang, J., Al-Hasani, H., and Levine, M. (2013). Intestinal dehydroascorbic acid (DHA) transport mediated by the facilitative sugar transporters, GLUT2 and GLUT8. J. Biol. Chem. 288, 9092-9101. doi: 10.1074/jbc.M112.436790

Corti, A., Casini, A., and Pompella, A. (2010). Cellular pathway for transport and efflux of ascorbate and dehydroascorbate. Arch. Biochem. Biophys. 500, 107-115. doi: 10.1016/j.abb.2010.05.014

Cura, A. J., and Carruthers, A. (2012). Role of monosaccharide transport proteins in carbohydrate assimilation, distribution, metabolism and homeostasis. Compr. Physiol. 2, 863-914. doi: 10.1002/cphy.c110024

Daruwala, R., Song, J., Koh, W. S., Rumsey, S. C., and Levine, M. (1999). Cloning and functional characterization of the human sodium-dependent vitamin C transporters hSVCT1 and hSVCT2. FEBS Lett. 460, 480-484. doi: 10.1016/S0014-5793(99)01393-9

Delwing, D., Bavaresco, C. S., Monteiro, S. C., Matté, C., Netto, C. A., and Wyse, A. T. (2006). alpha- Tocopherol and ascorbic acid prevent memory deficits provoked by chronic hyperprolinemia in rats. Behav. Brain Res. 168, 185-189. doi: 10.1016/j.bbr.2005.08.014

Doege, H., Schürman, A., Bahrenberg, G., Brauers, A., and Hans-Georg, J. (2000). GLUT8, a novel member of the sugar transport facilitator family with glucose transport activity. J. Biol. Chem. 275, 16275-16280. doi: $10.1074 / \mathrm{jbc} .275 .21 .16275$

Dorado-Marínez, C., Pereyra-Muñoz, N., Duran-Vázquez, A., Pedrosa-Rios, K., Borgonio, G., and Rivas-Arancibia, S. (1998). "Antioxidant effects of vitamins C and $\mathrm{E}$ on lipid peroxidation and behavior alterations caused by ozone exposure," in 28th Annual Meeting (Los Angeles, CA), 7-12.

Dröge, W. (2002). Free radical in the physiological control of cell function. Physiol. Rev. 82, 47-95. doi: 10.1152/physrev.00018.2001

Du, J., Cullen, J. J., and Buettner, G. R. (2012). Ascorbic acid: chemistry, biology and the treatment of cancer. Biochim. Biophys. Acta 1826, 443-457. doi: 10.1016/j.bbcan.2012.06.003

Erecińska, M., and Silver, I. A. (2001). Tissue oxygen tension and brain sensitivity to hypoxia. Respir. Physiol. 128, 263-276. doi: 10.1016/S0034-5687(01)00306-1

Fernández-Valle, C., Fregien, N., Wood, P. M., and Bunge, M. B. (1993). Expression of the protein zero myelin gene in axon-related Schwann cells linked to basal lamina formation. Development 119, 867-880.
Fillenbaum, G. G., Kuchibhatla, M. N., Hanlon, J. T., Artz, M. B., Pieper, C. F., Schmader, K. E., et al. (2005). Dementia and Alzheimer's disease in communityswelling elders taking vitamin C and/or vitamin E. Ann. Pharmacother. 39, 2009-2014. doi: 10.1345/aph.1G280

Fragoso, G., Robertson, J., Athlan, E., Tam, E., Almazan, G., and Mushynski, W. E. (2003). Inhibition of p38 mitogen-activated protein kinase interferes with cell shape changes and gene expression associated with Schwann cell myelination. Exp. Neurol. 183, 34-46. doi: 10.1016/S0014-4886(03)00101-8

Frei, B., England, L., and Ames, B. N. (1989). Ascorbate is an outstanding antioxidant in human blood plasma. Proc. Natl. Acad. Sci. U.S.A. 86, 6377-6381. doi: $10.1073 /$ pnas.86.16.6377

García Mde, L., Salazar, K., Millán, C., Rodríguez, F., Montecinos, H., Caprile, T., et al. (2005). Sodium vitamin C cotranporter SVCT2 is expressed in hypothalamic glial cells. Glia 50, 32-47. doi: 10.1002/glia.20133

Gess, B., Lohmann, C., Halfter, H., and Young, P. (2010). Sodium-dependent vitamin C transporter 2 (SVCT2) is necessary for the uptake of L-ascorbic acid into schwann cells. Glia. 58, 287-299. doi: 10.1002/glia.20923

Grant, M. M., Barber, V. S., and Griffiths, H. R. (2005). The presence of ascorbate induces expression of brain derived neurotrophic factor in SH-SY5Y neuroblastoma cells after peroxide insult, which is associated with increased survival. Proteomics 5, 534-540. doi: 10.1002/pmic.200300924

Grollman, A. P., and Lehninger, A. L. (1957). Enzymic synthesis of L-ascorbic acid in different animal species. Arch. Biochem. Biophys. 69, 458-467. doi: 10.1016/0003-9861(57)90510-6

Grümewald, R. A. (1993). Ascorbic acid in the brain. Brain Res. Rev. 18, 123-133. doi: 10.1016/0165-0173(93)90010-W

Grûnewald, R. A., and Fillenz, M. (1984). Release of ascorbate from a synaptosomal fraction of rat brain. Neurochem. Int. 6, 491-500. doi: 10.1016/01970186(84)90120-7

Haramoto, M., Tatemoto, H., and Muto, N. (2008). Essential role of ascorbic acid in neural differentiation and development: high levels of ascorbic acid 2glucoside effectively enhance nerve growth factor-induced neurite formation and elongation in PC12 cells. J. Health Sci. 54, 43-49. doi: 10.1248/jhs.54.43

Harrison, F. E., and May, J. M. (2009). Vitamin C function in the brain: vital role of the ascorbate transporter SVCT2. Free Radic. Biol. Med. 46, 719-730. doi: 10.1016/j.freeradbiomed.2008.12.018

Hasanein, P., and Shahidi, S. (2010). Effects of combined treatment with vitamin $\mathrm{C}$ and $\mathrm{E}$ on passive avoidance learning and memory in diabetic rats. Neurobiol. Learn. Mem. 93, 472-478. doi: 10.1016/j.nlm.2010.01.004

Huang, J., Agus, D. B., Winfree, C. J., Kiss, S., Mack, W. J., McTaggart, R. A., et al. (2001). Dehydroascorbic acid, a blood brain barrier transportable form of vitamin $\mathrm{C}$, mediates potent cerebroprotection in experimental stroke. Proc. Natl. Acad. Sci. U.S.A. 98, 11720-11724. doi: 10.1073/pnas.1713 25998

Huh, W. K., Lee, B. H., Kim, S. T., Kim, Y. R., Rhie, G. E., Baek, Y. W., et al. (1998). D-Erythroascorbic acid is an important antioxidant molecule in Saccharomyces cerevisae. Mol. Microbiol. 30, 895-903. doi: 10.1046/j.1365-2958.1998.01133.x

Jackson, P. S., and Strange, K. (1993). Volume-sensitive anion channels mediate swelling-activated inositol and taurine efflux. Am. J. Physiol. 265, C1489C1500.

Kagan, V. E., Shvedova, A., Serbinova, E., Khan, S., Swanson, C., Powell, R., et al. (1992). Dihydrolipoic acid- a universal antioxidant both in the membrane and in the aqueous phase: reduction of peroxyl, ascorbyl and chromanoxyl radicals. Biochem. Pharmacol. 44, 1637-1649. doi: 10.1016/0006-2952(92)90482-X

Kang, S. A., Jang, Y. J., and Park, H. (1998). In vivo dual effects of vitamin C on paraquat-induced lung damage: dependence on released metals from the damaged tissue. Free Radic. Res. 28, 93-107. doi: 10.3109/10715769809097880

Karanth, S., Yu, W. H., Walczewska, A., Mastronardi, C. A., and McCann, S. M. (2001). Ascorbic acid stimulates gonadotropin release by autocrine action by means of NO. Proc. Natl. Acad. Sci. U.S.A. 98, 11783-11788 doi: 10.1073/pnas.191369398

Lee, J. Y., Chang, M. Y., Park, C. H., Kim, H. Y., Kim, J. H., Son, H., et al. (2003). Ascorbate-induced differentiation of embryonic cortical precursors into neurons and astrocytes. J. Neurosci. Res. 73, 156-165. doi: 10.1002/jnr.10647

Levine, M., Daruwala, R. C., Park, J. B., Rumsey, S. C., and Wang, Y. (1998). Does vitamin C have prooxidant effect? Nature 395, 231. doi: 10.1038/26137

Li, Y., and Schellhorn, H. E. (2007). New developments and novel therapeutic perspectives for vitamin C. J. Nutr. 137, 2171-2184. 
Linster, C. L., and Van Schaftingen, E. (2007). Vitamin C: biosynthesis, recycling and degradation in mammals. FEBS J. 274, 1-22. doi: 10.1111/j.17424658.2006.05607.x

Mahfouz, M. M., and Kummerow, F. A. (2004). Vitamin C or vitamin B6 supplementation prevent the oxidative stress and decreases of prostacyclin generation in homocysteinemic rats. Int. J. Biochem. Cell Biol. 36, 1919-1932. doi: 10.1016/j.biocel.2004.01.028

Majewska, M. D., Bell, J. A., and London, E. D. (1990). Regulation of the NMDA receptor by redox phenomena: inhibitory role of ascorbate. Brain Res. 537, 328-332. doi: 10.1016/0006-8993(90)90379-P

Malo, C., and Wilson, J. X. (2000). Glucose modulates vitamin C transport in adult human small intestinal brush border membrane vesicles. J. Nutr. 130, 63-69.

Mardones, L., Ormazabal, V., Romo, X., Jaña, C., Blinder, P., Peña, E., et al. (2011). The glucose transporter-2 (GLUT2) is a low affinity dehydroascorbic acid transporter. Biochem. Biophys. Res. Commun. 410, 7-12. doi: 10.1016/j.bbrc.2011.05.070

Markarian, S. A., and Sargsyan, H. R. (2011). Electronic absortion spectra of ascorbic acid in water and water-dialkylsulfoxide mixtures. J. Appl. Spectrosc. 78, 6-10. doi: 10.1007/s10812-011-9418-9

May, J. M. (1999). Is ascorbic acid an antioxidant for the plasma membrane? FASEB J. 13, 995-1006.

May, J. M., Qu, Z. C., and Cobb, C. E. (2001). Recycling of the ascorbate free radical by human erythrocyte membranes. Free Radic. Biol. Med. 31, 117-124. doi: 10.1016/S0891-5849(01)00566-4

May, J. M., Qu, Z. C., and Qiao, H. (2009). Transfer of ascorbic acid across the vascular endothelium: mechanism and self-regulation. Am. J. Physiol. Cell Physiol. 297, C169-C178. doi: 10.1152/ajpcell.00674.2008

Mefford, I. N., Oke, A. F., and Adams, R. N. (1981). Regional distribution of ascorbate in human brain. Brain Res. 212, 223-226.

Michels, A. J., Joisher, N., and Hagen, T. M. (2003). Age-related decline of sodiumdependent ascorbic acid transport in isolated rat hepatocytes. Arch. Biochem. Biophys. 410, 112-120. doi: 10.1016/S0003-9861(02)00678-1

Morris, M. C., Beckett, L. A., Scherr, P. A., Hebert, L. E., Bennett, D. A., Field, T. S., et al. (1998). Vitamin E and vitamin C supplement use and risk of incident Alzheirmer Disease. Alzheirmer Dis. Assoc. Disord. 12, 121-126. doi: 10.1097/00002093-199809000-00001

Mueckler, M. (1994). Facilitative glucose transporters. Eur. J. Biochem. 219, 713-725. doi: 10.1111/j.1432-1033.1994.tb18550.x

Mueckler, M., and Thorens, B. (2013). The SLC2 (GLUT) family of membrane transporters. Mol. Aspects Med. 34, 121-138. doi: 10.1016/j.mam.2012. 07.001

Mühlhöfer, A., Mrosek, S., Schlegel, B., Trommer, W., Rozario, F., Böhles, H., et al. (2004). High-dose intravenous vitamin C is not associated with an increase of pro-oxidative biomarkers. Eur. J. Clin. Nutr. 58, 1151-1158. doi: 10.1038/sj.ejcn.1601943

Mustacich, D., and Powis, G. (2000). Thioredoxin reductase. Biochem. J. 346, 1-8. doi: 10.1042/bj3460001

Niki, E., Noguchi, N., Tsuchihashi, H., and Gotoh, N. (1995). Interaction among vitamin C, vitamin E, and $\beta$-carotene. Am. J. Clin. Nutr. 62, 1322S-1326S.

Nishikimi, M., Fukuyama, R., Minoshima, S., Shimizu, N., and Yagi, K. (1994). Cloning and chromosomal mapping of the human nonfunctional gene for Lgulono-gamma-lactone oxidase, the enzyme for L-ascorbic acid biosynthesis missing in man. J. Biol. Chem. 269, 13685-13688.

Nishikimi, M., and Yagi, K. (1991). Molecular basis for the deficiency in humans of gulonolactone oxidase, a key enzyme for ascorbic acid biosynthesis. Am. J. Clin. Nutr. 54, 1203S-1208S.

Padayatty, S. J., Katz, A., Wang, Y., Eck, P., Kwon, O., Lee, J. H., et al. (2003). Vitamin C as an antioxidant: evaluation of its role in disease prevention. J. Am. Coll. Nutr. 22, 18-35. doi: 10.1080/07315724.2003.107 19272

Parle, M., and Dhingra, D. (2003). Ascorbic acid: a promising memory-enhancer in mice. J. Pharmacol. Sci. 93, 129-135. doi: 10.1254/jphs.93.129

Podmore, I. D., Griffiths, H. R., Herbert, K. E., Mistry, N., Mistry, P., and Lunec, J. (1998). Vitamin C exhibits pro-oxidant properties. Nature 392, 559 doi: $10.1038 / 33308$

Podratz, J. L., Rodríguez, E., and Windebank, A. J. (2001). Role of the extracellular matrix in myelination of peripheral nerve. Glia. 35, 35-40. doi: 10.1002/glia. 1068
Puskas, F., Gergely, P. Jr., Banki, K., and Perl, A. (2000). Stimulation of the pentose phosphate pathway and glutathione levels by dehydroascorbate, the oxidized form of vitamin C. FASEB J. 14, 1352-1361. doi: 10.1096/fj.14.10.1352

Qiao, H., and May, J. M. (2009). Development of ascorbate transporters in brain cortical capillary endothelial cells in culture. Brain Res. 1208, 79-86. doi: 10.1016/j.brainres.2008.02.102

Qiu, S., Li, L., Weeber, E. J., and May, J. M. (2007). Ascorbate transport by primary cultured neurons and its role in neuronal function and protection against excitotoxicity. J. Neurosci. Res. 85, 1046-1056. doi: 10.1002/jnr.21204

Raić-Mlić, S., Svedruzić, D., Gazivoda, T., Marunović, A., Hergold-Brundić, A., Nagl, A., et al. (2000). Synthesis and antitumor activities of novel pyridine derivatives of 2, 3-O, O-dibenzyl-L-ascorbic acid and 4,5 didehydro-5,6-dideoxy-L- ascorbic acid. J. Med. Chem. 43, 4806-4811. doi: $10.1021 / \mathrm{jm} 0009540$

Rice, M. E., and Russo-Mena, I. (1997). Differential compartmentalization of brain ascorbate and glutathione between neurons and glia. Neuroscience 82, 1213-1223. doi: 10.1016/S0306-4522(97)00347-3

Richelle, M., Sabatier, M., Steiling, H., and Williamson, G. (2006). Skin bioavailability of dietary vitamin E, carotenoids, polyphenols, vitamin C, zin and selenium. Br. J. Nutr. 96, 227-238. doi: 10.1079/BJN20061817

Rumsey, S. C., and Levine, M. (1998). Absortion, transport, and disposition of ascorbic acid in humans. J. Nutr. Biochem. 9, 116-130. doi: 10.1016/S09552863(98)00002-3

Savini, I., Rossi, A., Pierro, C., Avigliano, L., and Catani, M. V. (2008). SVCT1 and SVCT2: key proteins for vitamin C uptake. Amino Acids 34, 347-355. doi: 10.1007/s00726-007-0555-7

Seitz, G., Gebhardt, S., Beck, J. F., Böhm, W., Lode, H. N., Niethammer, D., et al. (1998). Ascorbic acid stimulates DOPA synthesis and tyrosine hydroxylase gene expression in the human neuroblastoma cell line SK-N-SH. Neurosci. Lett. 244, 33-36. doi: 10.1016/S0304-3940(98)00129-3

Simpson, I. A., Dwyer, D., Malide, D., Monley, K., Travis, A., and Vannucci, S. J. (2008). The facilitative glucose transporter GLUT3: 20 years of distinction. Am. J. Physiol. Endocrinol. Metab. 295, E242-E253. doi: 10.1152/ajpendo.90388.2008

Siushansian, R., Dixon, S. J., and Wilson, J. X. (1996). Osmotic swelling stimulates ascorbate efflux from cerebral astrocytes. J. Neurochem. 66, 1227-1233. doi: 10.1046/j.1471-4159.1996.66031227.x

Steiling, H., Longet, K., Moodycliffe, A., Mansourian, R., Bertschy, E., Smola, H., et al. (2007). Sodium-dependent vitamin C transporter isoforms in skin: distribution, kinetics, and effect of UVB-induced oxidative stress. Free Radic. Biol. Med. 43, 752-762. doi: 10.1016/j.freeradbiomed.2007.05.001

Strange, K., and Jackson, P. S. (1995). Swelling-activated organic osmolyte efflux: a new role for anion channel. Kidney Int. 48, 994-1003. doi: 10.1038/ki.1995.381

Tolbert, B. M., Downing, M., Carlson, R. W., Knight, M. K., and Baker, E. M. (1975). Chemistry and metabolism of ascorbic acid and ascorbate sulfate. Ann. N.Y. Acad. Sci. 258, 48-69. doi: 10.1111/j.1749-6632.1975.tb29267.x

Tsukaguchi, H., Tokui, T., Mackenzie, B., Berger, U. V., Chen, X. Z., Wang, Y., et al. (1999). A family of mammalian Na+-dependent L-ascorbic acid transporters. Nature 399, 70-75. doi: 10.1038/19986

Valko, M., Leibfritz, D., Moncol, J., Cronin, M. T., Mazur, M., and Telser, J. (2007). Free radicals and antioxidants in normal physiological functions and human disease. Int. J. Biochem. Cell Biol. 39, 44-84. doi: 10.1016/j.biocel.2006.07.001

Valpuesta, V., and Botella, M. A. (2004). Biosynthesis of L-ascorbic acid in plants: new pathway for an old antioxidant. Trends Plant Sci. 9, 573-577. doi: 10.1016/j.tplants.2004.10.002

Vogler, S., Grosche, A., Pannicke, T., Ulbricht, E., Wiedemann, P., Reichenbach, A., et al. (2013). Hypoosmotic and glutamate-induced swelling of bipolar cells in the rat retina: comparison with swelling of Müller glial cells. J. Neurochem. 126, 372-381. doi: 10.1111/jnc.12307

Von Zastrow, M., Tritton, T. R., and Castle, J. D. (1984). Identification of Lascorbic acid in secretion granules of the rat parotid gland. J. Biol. Chem. 259, $11746-11750$.

Wells, W. W., and Xu, D. P. (1994). Dehydroascorbate reduction. J. Bioenerg. Biomembr. 26, 369-377. doi: 10.1007/BF00762777

Williams, N. H., and Yandell, J. K. (1982). Outer-sphere electron-transfer reactions of ascorbate anions. Aust. J. Chem. 35, 133-144. doi: 10.1071/CH9821133

Wilson, J. X. (2002). The physiological role of dehydroascorbic acid. FEBS Lett. 527, 5-9. doi: 10.1016/S0014-5793(02)03167-8 
Wilson, J. X. (2005). Regulation of vitamin C transport. Annu. Rev. Nutr. 25, 105-125. doi: 10.1146/annurev.nutr.25.050304.092647

Yamamoto, I., Tai, A., Fujinami, Y., Sasaki, K., and Okazaki, S. (2002). Synthesis and characterization of a series of novel monoacylated ascorbic acid derivates, 6-O-Acyl-2-O-alfa-D-glucopyranosyl-Lascorbic acids, as skin antioxidants. J. Med. Chem. 45, 462-468. doi: 10.1021/jm 010379f

Yan, J., Studer, L., and McKay, R. D. (2001). Ascorbic acid increases the yield of dopaminergic neurons derived from basic fibroblast growth factor expanded mesencephalic precursors. J. Neurochem. 76, 307-311. doi: 10.1046/j.14714159.2001.00073.x

Yu, D. H., Lee, K. H., Lee, J. Y., Kim, S., Shin, D. M., Kim, J. H., et al. (2004). Changes of gene expression profiles during neuronal differentiation of central nervous system precursors treated with ascorbic acid. J. Neurosci. Res. 78, 29-37. doi: $10.1002 /$ jnr.20220

Conflict of Interest Statement: The authors declare that the research was conducted in the absence of any commercial or financial relationships that could be construed as a potential conflict of interest.

Copyright $\odot 2015$ Figueroa-Méndez and Rivas-Arancibia. This is an open-access article distributed under the terms of the Creative Commons Attribution License (CC $B Y)$. The use, distribution or reproduction in other forums is permitted, provided the original author(s) or licensor are credited and that the original publication in this journal is cited, in accordance with accepted academic practice. No use, distribution or reproduction is permitted which does not comply with these terms. 